Aim of the study: Dynamic development of research on pain has resulted in the formulation of the concept of pre-emptive analgesia, which involves administration of analgesics before the first pain-producing stimulus appears. It is meant to prevent increased sensitivity to pain in the postoperative period. The aim of this study was to assess the possibilities of modifying the intensity of postoperative pain evaluated with the visual analogue scale (VAS) in patients after surgical treatment for breast neoplasm offered by pre-emptive analgesia.

Material and methods: The intensity of postoperative pain was measured immediately after the surgery as well as $6,12,18$, and 24 hours later in 100 women who had undergone surgery for breast tumour. The correlation between experienced pain and the type of analgesic administered pre-emptively, including metamizole, tramadol, ketoprofen, and placebo was examined. The effect of other correlates such as the extensiveness of surgery, systolic and diastolic blood pressure, and heart rate on the level of experienced pain as well as the usefulness of physiological parameters for its assessment were also analysed.

Results: The conducted study demonstrated the effectiveness of tramado $(p=0.004)$ and ketoprofen $(p=0.039)$ administered half an hour before the beginning of surgery, but there was no similar effect in the case of metamizole $(p=1.0)$. A positive correlation was observed between the level of experienced pain and blood pressure values $(p<0.001)$. Heart rate does not seem to be significantly linked with the intensity of experienced pain ( $p=$ 0.157).

Key words: postoperative pain, preemptive analgesia, breast cancer.

Contemp Oncol (Pozn) 2016; 20 (2): 158-164 DOI: $10.5114 /$ wo.2016.6007

\section{The effect of pre-emptive analgesia on the level of postoperative pain in women undergoing surgery for breast neoplasm}

\author{
Paweł Węgorowski ${ }^{1}$, Andrzej Stanisławek ${ }^{1}$, Renata Domżał-Drzewicka ${ }^{1}$, \\ Justyna Sysiak², Marcin Rząca ${ }^{1}$, Joanna Milanowska ${ }^{3}$, Mariola Janiszewska \\ Anna Dziubińska ${ }^{5}$
}

\author{
${ }^{1}$ Chair of Oncology and Environmental Health Care, Medical University of Lublin, Lublin, \\ Poland \\ ${ }^{2}$ The Second Department of Anaesthesiology and Intensive Care, Medical University \\ of Lublin, Lublin, Poland \\ ${ }^{3}$ The Institute of Applied Psychology, Medical University of Lublin, Lublin, Poland \\ ${ }^{4}$ Chair of Public Health, Medical University of Lublin, Lublin, Poland \\ ${ }^{5}$ Department of Computer Modelling and Metal Forming Technologies, Lublin University \\ of Technology, Lublin, Poland
}

\section{Introduction}

The care of the surgical patient should, above all, provide such a patient with a subjective feeling of comfort derived from appropriate relief of post-operative pain. This thesis is confirmed by the World Health Organization (WHO) declaration from $11^{\text {th }}$ October 2004, which said that "Pain relief should be a human right" [1]. The knowledge about the effects that pain, as a stress factor, has on the organism physiology confirms the considerable importance of pain control. Suffering from prolonged pain and activation of the sympathetic system related to it can lead to many negative consequences such as deterioration of respiratory mechanics, increased risk of perioperative myocardial ischaemia or changes in the hormonal system, resulting in depression of the immune system and healing process disorders [2]. Appropriate postoperative pain management not only provides patient's comfort, but also accelerates the recovery process, decreases the incidence of postoperative complications and mortality, and reduces treatment costs [3].

Despite the ongoing development of the methods of relieving postoperative pain, pain management in many surgical departments is insufficient [4]. Surgical trauma causes nociceptive sensitisation, which leads to intensified and prolonged suffering from postoperative pain. Acute postoperative pain develops into chronic pain in $10-50 \%$ of patients after such operations as inguinal hernioplasty, major or minor amputations, or breast surgery. Women undergoing surgical treatment of breast cancer, due to the very nature of such operations, are burdened with the risk of depression symptoms and their somatisation in the form of pain. This is why it is extremely important to prevent nociceptive sensitisation by means of appropriate perioperative pain control in such a group of patients [5]. In an attempt to minimise the psychogenic component of pain and negative feelings of patients related to breast surgery, in the process of treatment, whenever possible, breast-conserving surgery and immediate breast reconstruction are performed [6].

The patient's lifestyle [7] and neglecting the procedures of cancer prophylaxis [8] have a considerable effect on the feeling of pain and the ability to cope with it, and also on the very process of neoplasm formation, breast cancer included. 
The strategy of pre-emptive analgesia assumes counteracting the development of hyperalgesia in the postoperative period thanks to the modification of particular phases of pain response formation, already in the preoperative period, by means of nonsteroidal anti-inflammatory drugs (NSAID), paracetamol, opioids, and the techniques of conduction anaesthesia using local anaesthetics. The use of pre-emptive analgesia allows counteraction of sensitisation in the first phase, i.e. connected with surgical trauma. However, combining it with postoperative multimodal analgesia secures the patient against sensitisation in the second phase of nociceptive response as well [9].

The aim of the present study was to evaluate the effects of analgesics used in pre-emptive analgesia on the level of postoperative pain intensity felt by female patients after surgical treatment of breast cancer.

\section{Material and methods}

The study included 100 (100\%) randomly selected patients aged $58.58 \pm 12.01$ years on average, operated on for breast cancer in the $5^{\text {th }}$ Department of Oncological Surgery with Subdepartment of Gastrointestinal Surgery and Subdepartment of One-Day Surgery and Operating Suit, St. John's Oncology Centre in Lublin. The patients were operated on in the period between November 2012 and June 2013. The operations included simple mastectomy or modified radical mastectomy, breast-conserving surgeries such as quadrantectomy, wide local excision, and sentinel lymph node biopsy. Consent no KE-0254/137/2012 was obtained from the Bioethics Committee, Medical University of Lublin in order to conduct the study, and participation in the study was voluntary.

The study with double-blind trial consisted of two stages. The study group was divided into four subgroups including 25 people each. The division was conditioned by the study assumption (administration of three different analgesics and placebo). In the first stage the female patients, prepared for surgery, received an analgesic (metamizole $1.0 \mathrm{~g}$, ketoprofen $100 \mathrm{mg}$, or tramadol $100 \mathrm{mg}$ ) or placebo $(0.9 \% \mathrm{NaCl}) 30$ minutes before induction of anaesthesia. These substances were administered with identical undescribed $20-\mathrm{ml}$ syringes. Anaesthesia was induced using propofol in the dose of $2 \mathrm{mg} / \mathrm{kg}$ of body mass. Cis-atr- akurium in the dose of $0.1 \mathrm{mg} / \mathrm{kg}$ of body mass was used for muscle relaxation. For the maintenance of anaesthesia there a mixture of oxygen (33\%) and nitrous oxide (66\%), sevoflurane (1 MAC) and fentanyl was used in the dose of $0.1-0.2 \mathrm{mg}$.

In the second stage, examinations were conducted immediately after surgery and $6,12,18$, and 24 hours after surgery. In each patient there heart rate and arterial blood pressure were measured, and then pain intensity using a visual analogue scale (VAS).

The study results were analysed statistically. The values of the analysed measurable parameters were presented using mean value and standard deviation. In the case of immeasurable values frequencies and percentages were used. To compare the studied groups there repeated measured analysis of variance were used, and then contrast analysis with simple contrast, in which the first measurement of pain was established as the reference level. Particular measurements of pain were set as intra-object factors, whereas drugs used in pre-emptive analgesia were selected to be inter-object factors. In the case of analysis of other factors, e.g. the range of surgery, or dose of analgesic used in general anaesthesia, they were introduced as covariants. The $\chi^{2}$ test was used to examine the relations between quality variables. In order to examine the relationship between two characters, the significance of Pearson correlation coefficient was tested. The correlation coefficient was statistically significant for $p<0.05$. Statistical analysis was conducted using the software SPSS 14.0 PL.

\section{Results}

The subject of the evaluation was the influence of the drug administered in pre-emptive analgesia on the level of pain intensity assessed in VAS. The pain intensity of patients who received metamizole, tramadol, and ketoprofen was compared to the control group. Significant differences were shown in the values of pain intensity between particular groups $\mathrm{F}=6.087, p=0.006$ (Table 1).

The results show that pain intensity was significantly lower in the patients who received tramadol $(p=0.004)$ or ketoprofen $(p=0.039)$ in pre-emptive analgesia in relation to pain intensity in the control group. No statistically sig-

Table 1. The influence of the drugs administered in pre-emptive analgesia on the level of pain intensity

\begin{tabular}{|c|c|c|c|c|c|c|c|c|}
\hline \multirow[t]{2}{*}{ Pain intensity } & \multicolumn{2}{|c|}{ Metamizole } & \multicolumn{2}{|c|}{ Tramadol } & \multicolumn{2}{|c|}{ Ketoprofen } & \multicolumn{2}{|c|}{ Placebo } \\
\hline & $\begin{array}{l}\text { mean } \\
\text { value }\end{array}$ & SD & $\begin{array}{l}\text { mean } \\
\text { value }\end{array}$ & SD & $\begin{array}{l}\text { mean } \\
\text { value }\end{array}$ & SD & $\begin{array}{l}\text { mean } \\
\text { value }\end{array}$ & SD \\
\hline immediately after surgery & 3.56 & 1.158 & 2.88 & 0.881 & 2.96 & 0.889 & 3.80 & 1.190 \\
\hline after 6 hours & 2.44 & 0.961 & 1.80 & 0.764 & 1.72 & 0.737 & 2.44 & 0.870 \\
\hline after 12 hours & 1.76 & 0.831 & 1.48 & 0.586 & 1.36 & 0.569 & 2.0 & 0.816 \\
\hline after 18 hours & 1.16 & 0.898 & 0.68 & 0.557 & 0.72 & 0.678 & 1.16 & 0.800 \\
\hline after 24 hours & 0.8 & 0.645 & 0.48 & 0.510 & 0.48 & 0.510 & 0.64 & 0.638 \\
\hline \multirow[t]{2}{*}{$\begin{array}{c}\text { difference betweer } \\
\text { values }\end{array}$} & \multicolumn{2}{|c|}{0.045} & \multicolumn{2}{|c|}{$0.552^{\star}$} & \multicolumn{2}{|c|}{$0.444^{\star}$} & & \\
\hline & \multicolumn{2}{|c|}{1.000} & \multicolumn{2}{|c|}{$0.004^{*}$} & \multicolumn{2}{|c|}{$0.039^{\star}$} & & \\
\hline
\end{tabular}




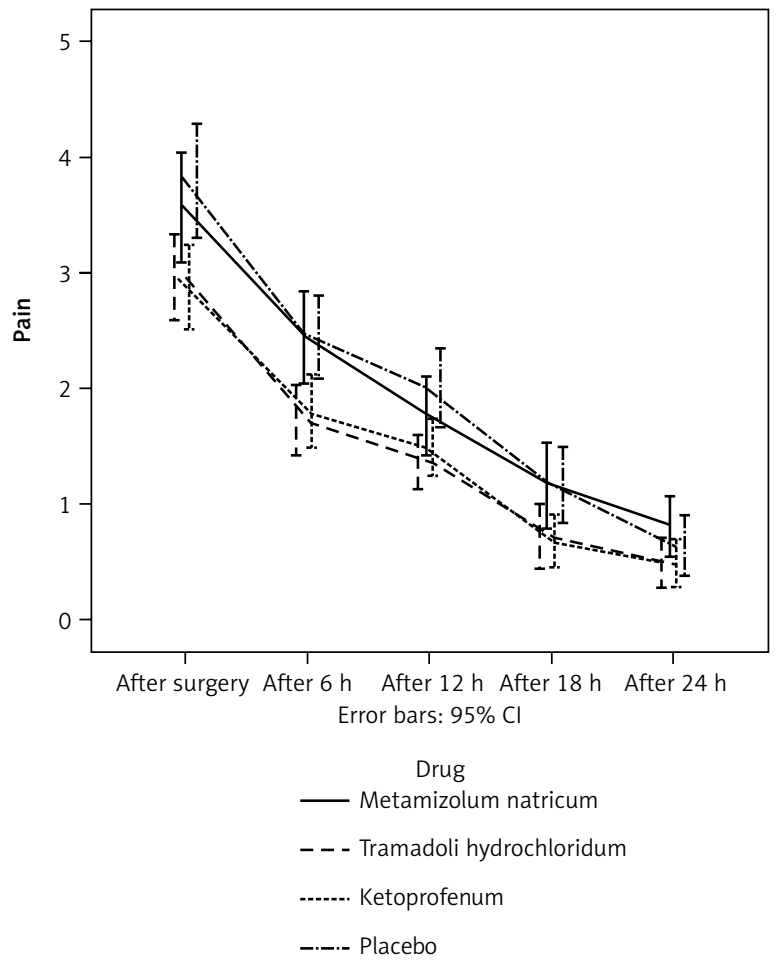

Fig. 1. Changes in pain intensity in time in relation to the administered analgesic nificant differences were found in the group that received metamizole $(p=1.00)$.

In all analysed groups pain intensity decreased with time. No statistically significant differences were shown in the dynamics of decrease of pain intensity between particular groups that received, respectively, metamizole, tramadol, ketoprofen, or placebo ( $F=1.36, p=0.190)$ (Fig. 1).

The intensity of postoperative pain significantly falls during the first 6 hours after the surgery $(F=224.495$, $p<0.001)$. Between $6^{\text {th }}$ and $12^{\text {th }}$ hour after the surgery pain intensity shows a decreasing tendency, and this decrease is statistically significant $(F=28.287, p<0.001)$. A significant fall in postoperative pain intensity evaluated in VAS is also observed between the $12^{\text {th }}$ and $18^{\text {th }}$ hour after the surgery $(F=85.336, p<0.001)$. In the period between the $18^{\text {th }}$ and $24^{\text {th }}$ hour after the surgery the intensity of postoperative pain is still decreasing significantly $(F=16.026$, $p<0.001$ ). The observed relationship was similar in all of the analysed groups, independently of the drug used in pre-emptive analgesia.

The study also evaluated whether the values of systolic pressure correlate with the intensity of postoperative pain, and if they can be considered as an additional indicator in pain evaluation. The analysis showed a positive correlation between pain intensity and systolic arterial blood pressure $\left(r=0.386^{\star}, p<0.001\right)$ (Fig. 2).

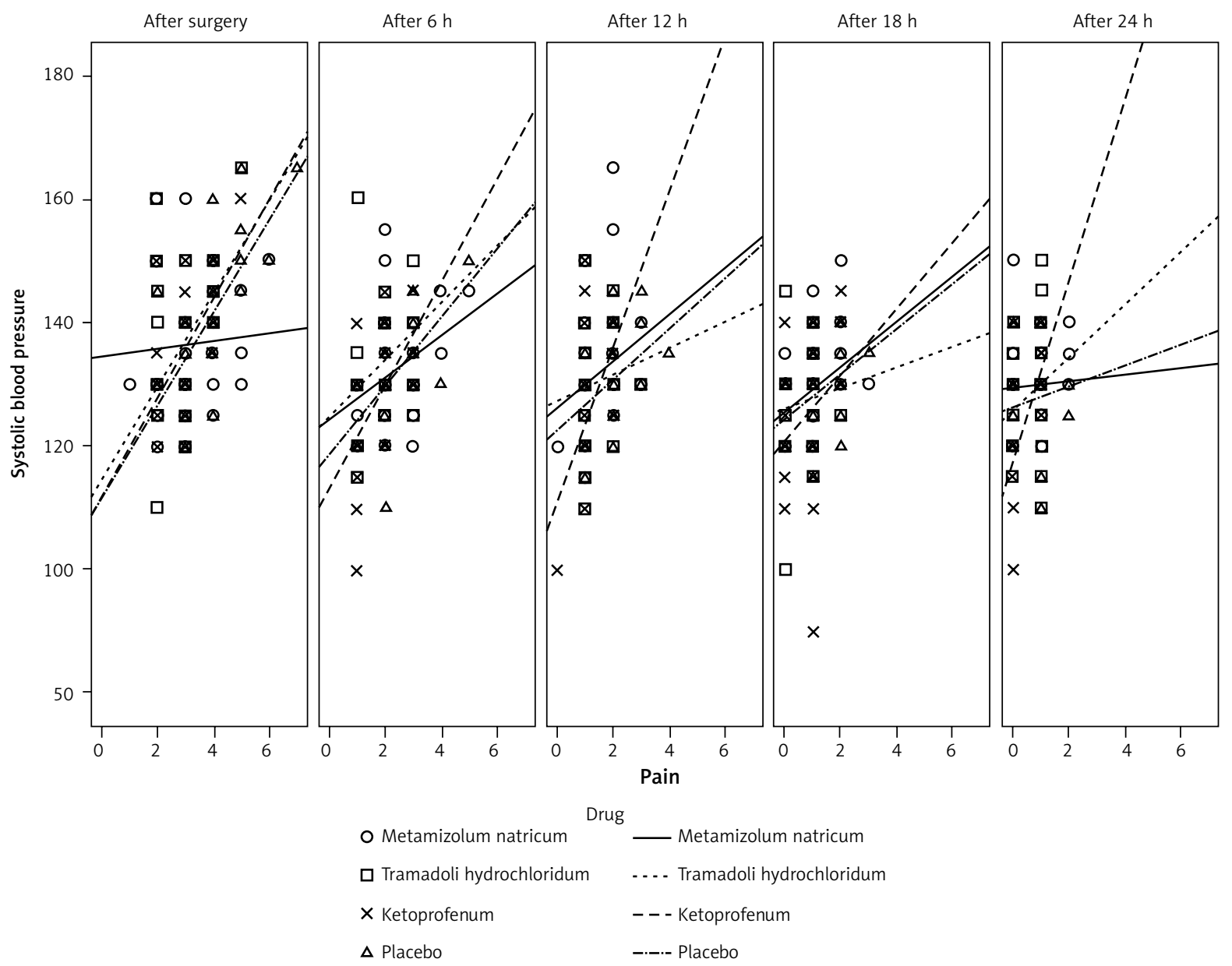

Fig. 2. Correlation between systolic pressure and pain intensity 
In all of the analysed groups systolic pressure fell, but this fall was statistically significant only between the 0 and $6^{\text {th }}$ hour after the surgery $(F=83.009, p<0.001)$ and between $12^{\text {th }}$ and $18^{\text {th }}$ hour after the surgery $(F=27.418$, $p<0.001)$. No statistically significant fall was observed between $6^{\text {th }}$ and $12^{\text {th }}$ hour after the surgery $(F=1.959$, $p=0.165)$ and between the $18^{\text {th }}$ and $24^{\text {th }}$ hour $(F=0.176$, $p=0.676)$. The only exception was the group of patients that received tramadol in pre-emptive analgesia, in which the decrease in systolic pressure between $6^{\text {th }}$ and $12^{\text {th }}$ hour after the surgery was also statistically significant $(p=0.02)$ (Fig. 3).

No significant differences were observed in the dynamics of changes in systolic pressure in relation to the drug administered in pre-emptive analgesia $(F=1.137, p=0.33)$.

And, similarly, an assessment was conducted of the relationship between the values of diastolic arterial blood pressure and pain intensity evaluated according to VAS, at subsequent hours after the surgery. It was shown that there is a correlation between the intensity of postoperative pain and the value of diastolic pressure in the studied population ( $\left.r=0.446^{*}, p<0.001\right)$ (Fig. 4).

When analysing the dynamics of changes in the values of diastolic pressure in time it was observed that the pressure fell with time (Fig. 5).

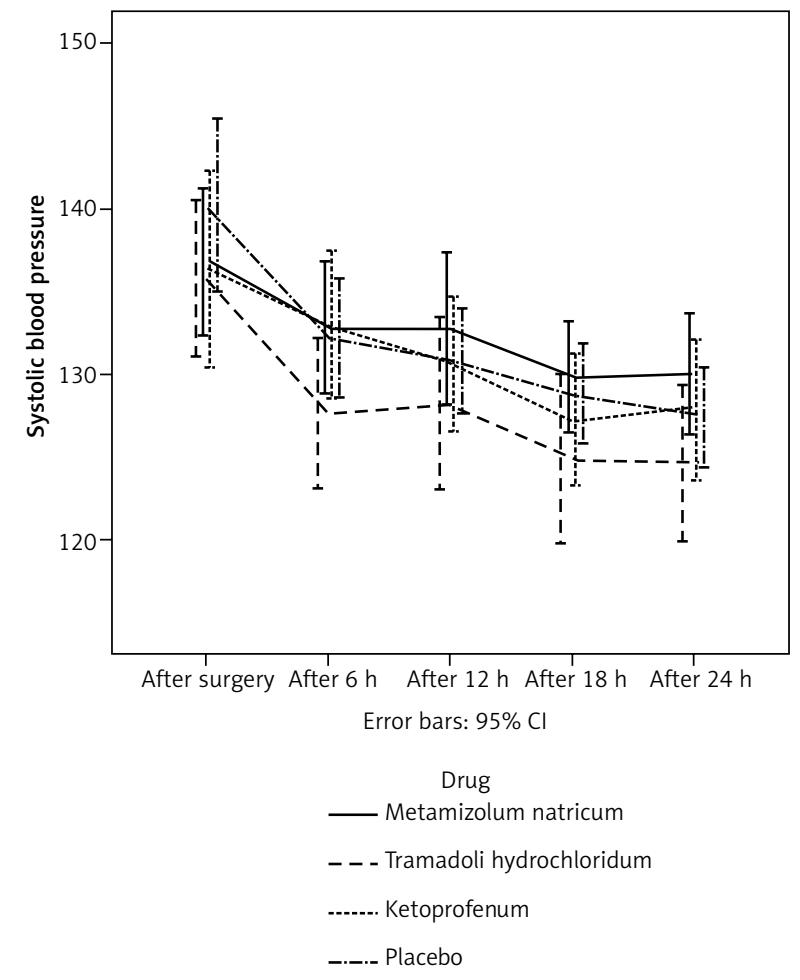

Fig. 3. Changes in systolic pressure in time

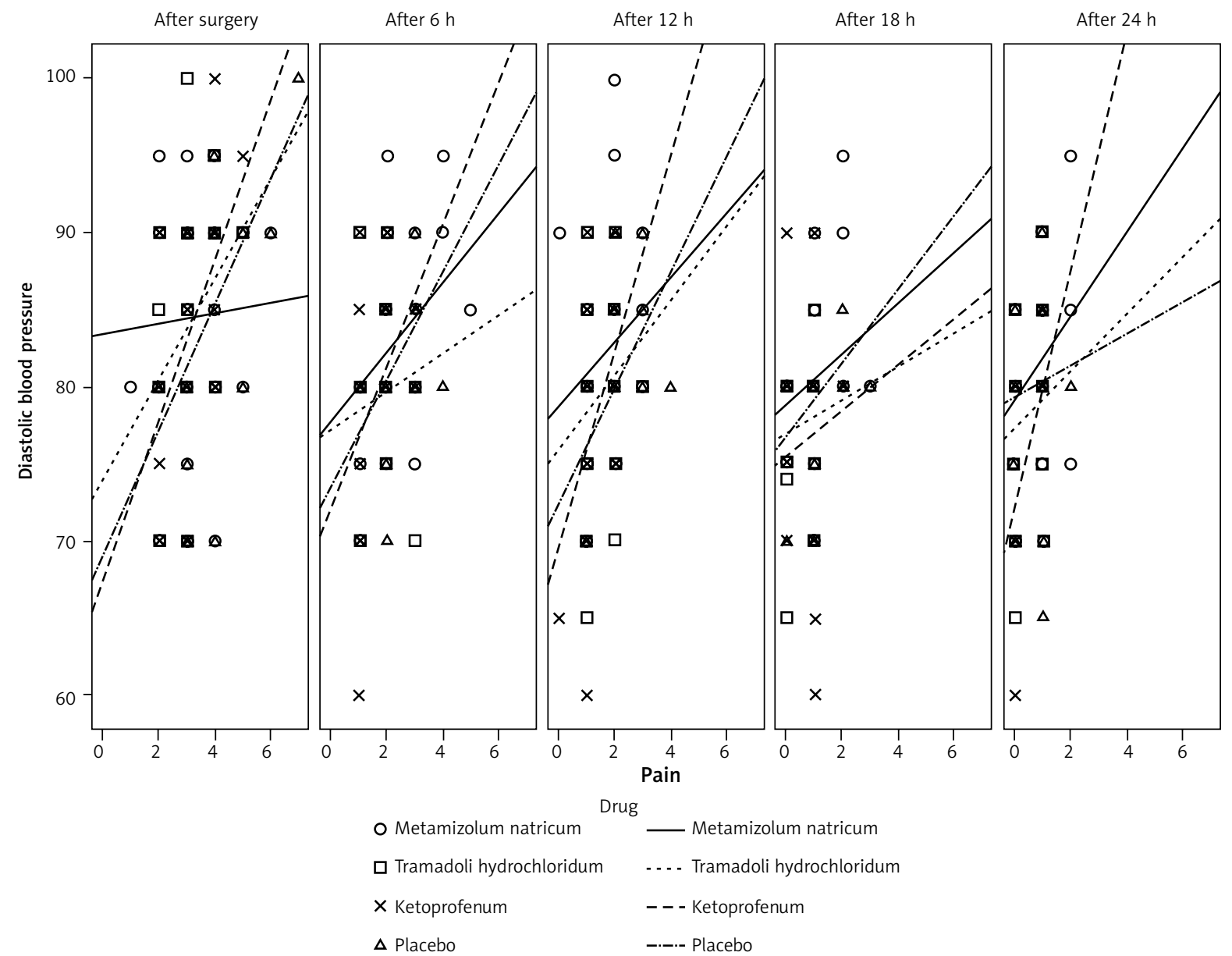

Fig. 4. Correlation between diastolic pressure and pain intensity 


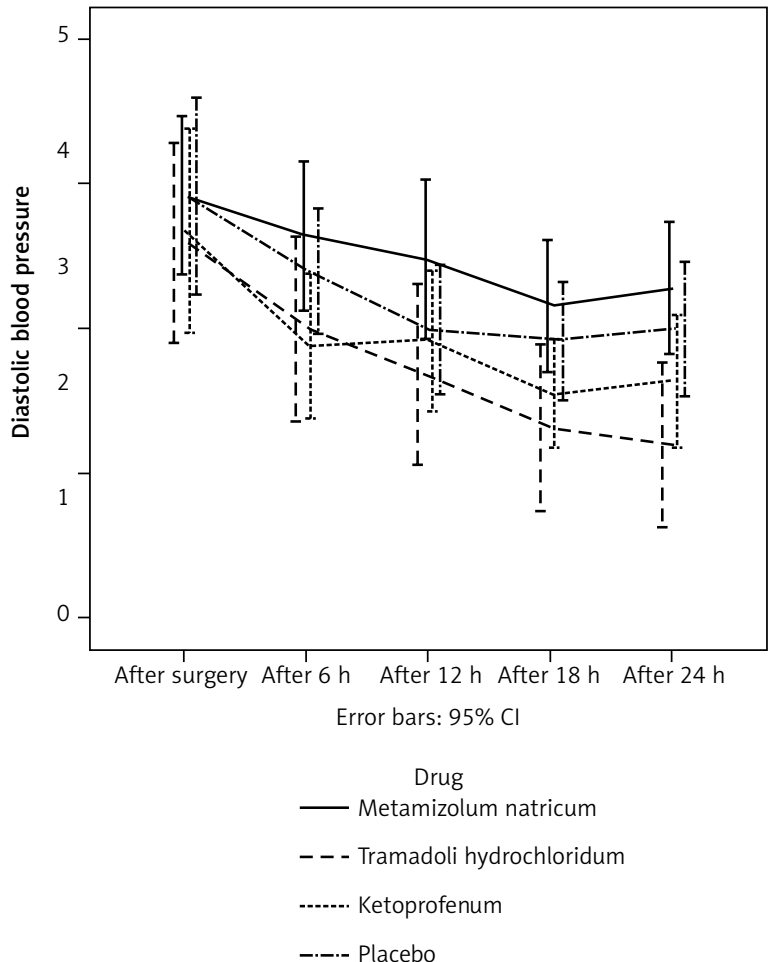

Fig. 5. Changes in diastolic pressure in time
An examination was conducted to discover whether this decrease was statistically significant in the subsequent time intervals, i.e. immediately after the surgery, $6,12,18$, and 24 hours after the surgery. Diastolic pressure significantly fell during the first 6 hours after the surgery $(F=19.547, p<0.001)$. Between the $6^{\text {th }}$ and $12^{\text {th }}$ hour after the surgery diastolic pressure continued to decrease, but it was not statistically significant $(F=4.055, p=0.05)$. A significant decrease in diastolic pressure was also observed between the $12^{\text {th }}$ and $18^{\text {th }}$ hour after the surgery $(F=8.850, p=0.004)$. However, there was no significant difference between the values of the diastolic pressure measured at the $18^{\text {th }}$ and $24^{\text {th }}$ hours after the surgery $(F=0.201$, $p=0.655)$. No significant difference was shown in the dynamics of changes in diastolic pressure in relation to the type of drugs used in pre-emptive analgesia ( $F=3.115$, $p>0.05)$.

In the study the heart rate was analysed as a factor that might correlate with the intensity of postoperative pain. The analysis showed no significant correlation between pulse and the intensity of pain evaluated in VAS, after the surgery ( $r=0.143, p=0.157$ ) (Fig. 6).

\section{Discussion}

Transmission of pain stimuli from the tissues damaged during surgery to the central nervous system, where pain

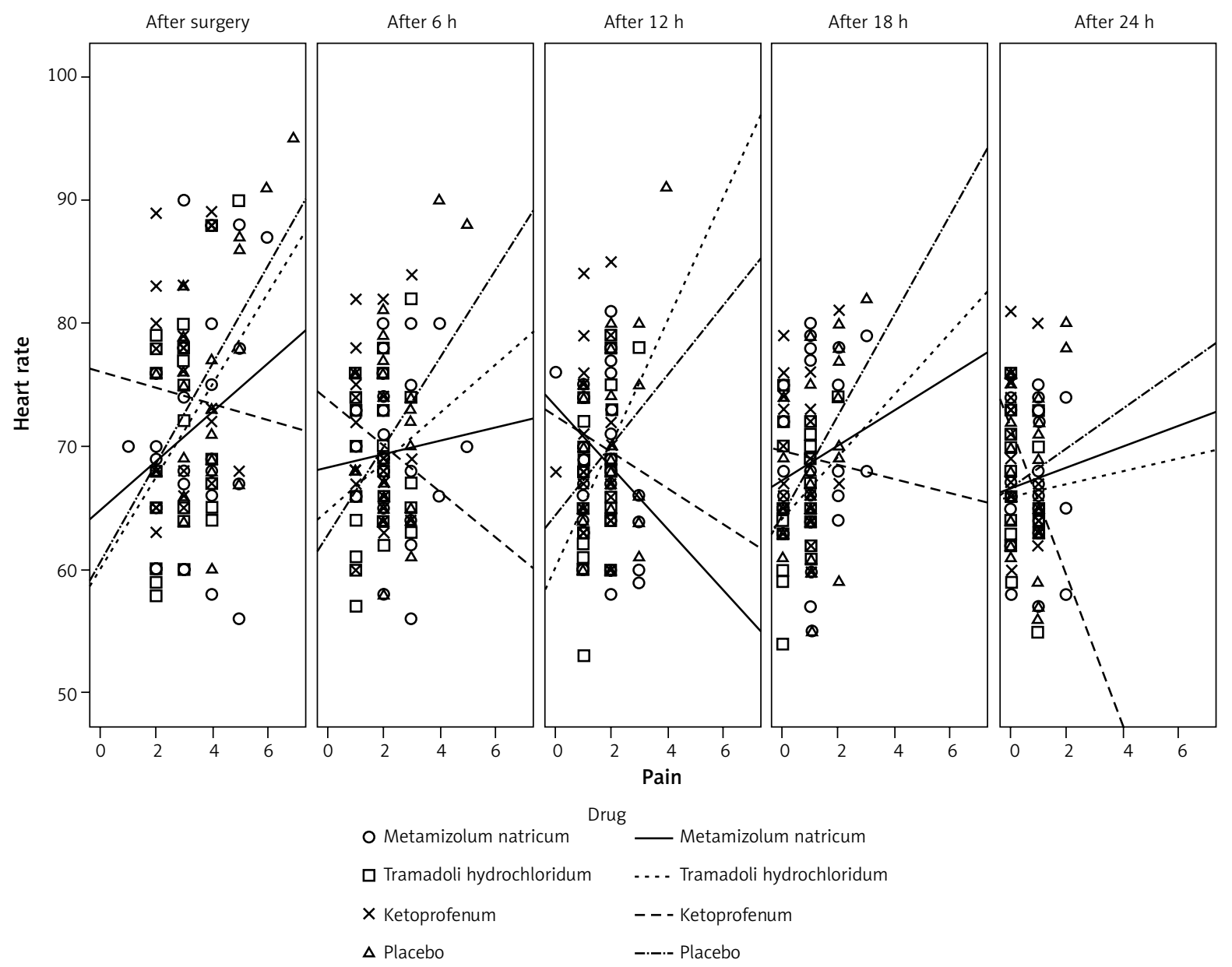

Fig. 6. Correlation between pulse and pain intensity 
is perceived, does not occur in a single way, but it starts a cascade of reactions that lead to sensitisation of the peripheral and central pain pathways. This phenomenon causes the occurrence of negative effects such as hyperalgesia, allodynia, or chronic pain, which lasts for a long time after the tissues have healed. The results of experimental studies suggest that it is possible and advisable to prevent neurophysiological and biochemical effects of a pain stimulus on the peripheral and central nervous systems. Such a procedure seems better than starting pain control after changes have occurred in the neurons responsible for pain transmission [10].

The effectiveness of pre-emptive analgesia and its advantage over the conventional methods of postoperative pain management still arouse controversy. The following reviews of articles on the effectiveness of pre-emptive analgesia provide different results. Many authors prove that pre-emptive analgesia is an effective form of postoperative pain control; nevertheless, there are a number of studies the authors of which claim that pre-emptive analgesia does not have any advantage over postoperative analgesia [11].

Studies prove that the effectiveness of pre-emptive analgesia can vary depending on the site and type of the surgery. The studies by Aida et al. [12], for instance, showed that pre-emptive analgesia using morphine administered extradurally turned out to be effective only in the case of mastectomy and operations of the hip, but not in the case of hysterectomy or hernioplasty. Another factor that can influence the effectiveness of pre-emptive analgesia can be the type of analgesic.

The study evaluated the influence of analgesics administered in pre-emptive analgesia on the intensity of postoperative pain in female patients operated on for breast cancer.

According to the classification of operations in relation to their extent and expected intensity of postoperative pain, breast surgery belongs to the first category, where postoperative pain is $\leq 4$ points in the VAS. In the case of operations that belong to this category the recommended pain management procedure in pre-emptive analgesia is intravenous administration of non-opioid pain medications.

Following the recommendation described above, in this study the decision was taken to use analgesics dedicated to relieve mild to moderate pains, which can be administered both before and after operations, i.e. metamizole, ketoprofen, and tramadol.

In the available literature the authors pay attention to the importance in pre-emptive analgesia of the appropriate time of analgesic administration or introduction of a procedure, e.g. introducing an extradural catheter, so that the effects of the administered drug exceed the action of the first nociceptive stimulus [13]. Consequently, in this study analgesics were administered intravenously 30 minutes before the first pain stimulus, i.e. skin incision, so that the onset of the drugs action, i.e. 20-30 minutes after administration, would coincide with the beginning of pain stimulation. The medications used in this study are characterised by similar terminal half-lives, which amount to 4-5 hours. All of them are metabolised in the liver and excreted through the kidneys. Consequently, the only factor that can differentiate their effectiveness in pre-emptive analgesia appears to be the different mechanism of action of the administered medications [14].

Analysis of the degree of postoperative pain intensity was conducted using the VAS immediately after the surgery and 6, 12, 18, and 24 hours after the surgery.

The mean intensity of postoperative pain was 3.3 points in VAS. It was shown that pain intensity was significantly lower in the patients who had received ketoprofen ( $p=0.039)$ or tramadol $(p=0.004)$ in pre-emptive analgesia. Metamizole proved ineffective $(p=1.0)$.

In their studies on the effectiveness of intravenously-administered ketoprofen in pre-emptive analgesia in patients operated on for breast cancer, Pirya et al. [15] proved that this drug causes significant postoperative pain relief, which confirms the results of our study.

Gehling et al. [16] also evaluated the effectiveness of administration of non-opioid pain medications prior to breast cancer operations as postoperative analgesia prophylaxis. The authors failed to prove the effectiveness of the analysed drugs in pre-emptive analgesia in breast surgery.

In our study, as well as ketoprofen, tramadol also turned out to be effective in reducing postoperative pain intensity. These results differ from the ones presented by Wordliczek et al. [17], who examined the influence of tramadol on pain intensity after hemicolectomy. According to the authors, tramadol did not cause a significant reduction of pain intensity evaluated in VAS after the operation. The effectiveness of tramadol administered in pre-emptive analgesia, however, can be confirmed by significantly lower use of tramadol administered in PCA-IV in the postoperative period, which was observed by the authors of the described study.

Our study showed a lack of effectiveness of metamizole administered in pre-emptive analgesia in reducing the intensity of postoperative pain. These results were confirmed by the experiment of Prado and Pontes [18], who, when experimenting on adult rats, showed a lack of effectiveness of metamizole administered in pre-emptive analgesia in preventing postoperative allodynia.

In professional literature a lot of attention is paid to physiological factors such as systolic and diastolic arterial blood pressure, as well as heart rate, which can be indirect indicators of acute pain intensity level. The increase in both arterial blood pressure and heart rate under the influence of pain is caused by the stimulation of the autonomic sympathetic system and release of catecholamines from the adrenal medulla [19].

In their studies Stovner et al. [20] suggested that there is a correlation between blood pressure values and pain felt by patients, and the knowledge of this dependence may be an important factor in improving pain control. Our studies confirm Stovner's suggestions by showing a positive correlation between the intensity of postoperative pain and the values of systolic blood pressure $(p<0.001)$. However, no significant difference was found in the values of systolic blood pressure in particular groups receiving tramadol, ketoprofen, metamizole, or placebo in pre-emptive analgesia. 
Different results, however, were obtained by Oyiadey et al. [21], who evaluated changes in arterial blood pressure in healthy volunteers subjected to pain stimuli. They showed that a rise in pain intensity causes a significant increase in the values of systolic pressure; however, there is no such dependence between pain and diastolic pressure.

In the studied group no significant relationship was shown between the values of heart rate and intensity of postoperative pain $(p=0.157)$. Also, the studies conducted by Sarabia Cachadiña et al. [22] on the relationship between the pulse and pain felt by patients after amputations of the lower extremity did not show a significant dependence between these factors, at the same time failing to prove the usefulness of measuring heart rate for the evaluation of pain intensity.

The latest study results published by Meeuse et al. [23] also prove that an increase in heart rate values may correspond with pain felt by the patient, but it cannot be considered an effective tool for pain intensity assessment.

After comparing the study results with the results published by foreign authors it appears that the assessment of heart rate and arterial blood pressure values can be helpful in the evaluation of postoperative pain, but they cannot be used alone, independently of the other indicators of pain felt by the patient.

The study implies that:

1. The use of pre-emptive analgesia brings positive effects (pain felt by operated women decreased on average by 3.3 points in VAS).

2. Not all pain-relieving medications have an equal effect on the reduction of the feeling of postoperative pain (positive effects on the feeling of pain were achieved after administration of ketoprofen and tramadol).

3. Further studies should be conducted on individual effects of pre-emptive analgesia since a number of studies present different results, which makes this method still a subject of much controversy.

The authors declare no conflict of interest.

\section{References}

1. Niv D, Devor M; European Federation of IASP Chapters. Position paper of the European Federation of IASP Chapters (EFIC) on the subject of pain management. Eur J Pain 2007; 11: 487-9.

2. Macintyre PE. Acute pain management: scientific evidence. A.N.Z.C.A., Sidney 2010 .

3. Mayzner-Zawadzka E, Błaszczyk E, Serednicki W, et al. Uśmierzanie bólu pooperacyjnego - zalecenia. Ból 2005; 6 (Special Issue): 5-12.

4. American Society of Anesthesiologists Task Force on Acute Pain Management. Practice guidelines for acute pain management in the perioperative setting. Anesthesiology 2004; 100: 1573-81.

5. Oniszczenko W, Laskowska A. Emotional reactivity, coping style and cancer trauma symptoms. Arch Med Sci 2014; 10: 110-16.

6. Maślach D, Krzyżak M, Szpak A, Bojar I, Bielska-Lasota M, Owoc A. The breast-conserving surgery of women with brestcancer in Podlaskie Voivodeship (Poland). Population study. Ann Agric Environ Med 2013; 20: 395-400.

7. Pięta B, Chmaj-Wierzchowska K, Opala T. Life style and risk of development of breast and ovarian cancer. Ann Agric Envirom Med 2012; 19: 379-84.
8. Bojar I, Biliński P, Boyle P, Zatoński W, Marcinkowski JT, WojtyłaA. Prevention of female reproductive system cancer among rural and urban Polish pregnant women. Ann Agric Environ Med 2011; 18: 183-88.

9. Woolf CJ, Chong MS. Preemptive analgesia - treating postoperative pain by preventing the establishment of central sensitization. Anesth Analg 1993; 7: 362-67.

10. Dahl JB, Møiniche S. Pre-emptive analgesia. Br Med Bull 2004; 71: 13-27.

11. Niv D, Lang E, Devor M. The effect of preemptive analgesia on acute postoperative pain. Minerva Anestesiol 1999; 65: 127-40.

12. Aida S, Baba H, Yamakura T, Taga K, Fukuda S, Shimoji K. The effectiveness of preemptive analgesia varies according to the type of surgery: a randomized, double-blind study. Anesth Analg 1999; 89: 711-6.

13. Katz J. Pre-emptive analgesia: importance of timing. Can J Anaesth 2001; 48: 105-14.

14. McCormack K. Non-steroidal anti-inflammatory drugs and spinal nociceptive processing. Pain 1994; 59: 9-44.

15. Priya V, Divatia JV, Sareen R, Upadhye S. Efficacy of intravenous ketoprofen for preemptive analgesia. J Postgrad Med 2002; 48: 109-12.

16. Gehling M, Arndt C, Behrendt IC, Wulf H, Eberhart LHJ. Is the prophylactic use of non-opioids for post- operative analgesia always indicated? A randomized controlled trial in breast surgery. Ambulatory Surgery 2010; 16: 93-9.

17. Wordliczek J, Banach M, Garlicki J, Jakowicka-Wordliczek J, Dobrogowski J. Influence of pre- or intraoperational use of tramadol (preemptive or pre-ventive analgesia) on tramadol requirement in the early postoperative period. Pol J Pharmacol 2002; 54: 693-97.

18. Prado WA, Pontes RM. Presurgical ketoprofen, but not morphine, dipyrone, diclofenac or tenoxicam, preempts post-incisional mechanical allodynia in rats. Braz J Med Biol Res 2002; 35: 111-19.

19. Lewis KS, Whipple JK, Michael KA, Quebbeman EJ. Effect of analgesic treatment on the physiological consequences of acute pain. Am J Hosp Pharm 1994; 51: 1539-1554.

20. Stovner LJ, Hagen K, Tronvik E. Relationship between BP and pain: The Nord-Trřndelag Health Survey. ACNR 2011; 11: 28-30.

21. Oyadeyi AS, Afolabi AO, Ajao FO, Ibironke GF. Resting blood pressure and blood pressure reactivity: contributions to experimental pain report in healthy males. World Res I Med Sci 2006; 1: 90-2.

22. Sarabia Cachadiña E, Granados García P, Tonon Da Luz SC, Goya Esteban R, Barquero Pérez O, Naranjo Orellana J, Berral de la Rosa FJ. Heart rate variability and phantom pain in male amputees: Application of linear and nonlinear methods. J Rehabil Res Dev 2013; 50: 449-54.

23. Meeuse JJ, Löwik MS, Löwik SA, et al. Heart rate variability parameters do not correlate with pain intensity in healthy volunteers. Pain Med 2013; 10.1111/pme.12133.

24. Møiniche S, Kehlet H, Dahl JB. A qualitative and quantitative systematic review of preemptive analgesia for postoperative pain relief: the role of timing of analgesia. Anesthesiology 2002; 96: 725-41.

25. Ong CK, Lirk P, Seymour RA, Jenkins BJ. The efficacy of preemptive analgesia for acute postoperative pain management: a meta-analysis. Anesth Analg 2005; 100: 757-73.

\section{Address for correspondence}

\section{Renata Domżał-Drzewicka}

Chair of Oncology and Environmental Health

Faculty of Nursing and Health Sciences

Medical University of Lublin

Staszica 4-6

20-093 Lublin, Poland

e-mail: renatadd@op.pl

Submitted: 25.09 .2014

Accepted: 20.07 .2015 